\title{
Patrones de cambio de las redes personales de inmigrantes en Cataluña
}

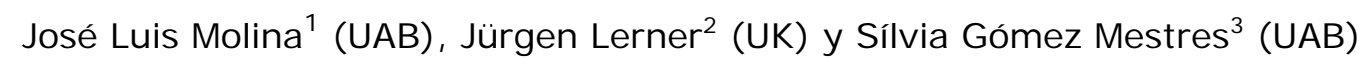

\section{Resumen}

A través del análisis de las redes personales de personas emigradas en Cataluña (España) en dos oleadas separadas entre un año y medio y dos años, se ha podido establecer un modelo general de cambio y una codificación de los factores que explican esos cambios a partir de los testimonios de sus protagonistas.

Los colectivos estudiados han sido argentinos $(n=25)$, dominicanos $(n=16)$, marroquíes $(n=13)$ y personas de Senegal y Gambia $(n=13)$. Así, mientras especialmente la obtención de un empleo y la participación en cursos y actividades deportivas representan cambios en la dirección del modelo general (evolución), el matrimonio y el nacimiento de hijos, la pertenencia a asociaciones étnicas, los viajes y las visitas de familiares y amigos representan cambios en la dirección inversa (involución). Gracias al uso de metarepresentaciones de esas redes personales ha sido posible comparar las redes de una misma persona en las dos oleadas $y$, al mismo tiempo, agregar y comparar las redes por colectivos, manifestándose diferencias en las modalidades de adaptación y cambio entre los diferentes colectivos.

Palabras clave: análisis dinámico - redes personales - emigración - métodos mixtos - análisis de redes sociales - visualización.

\begin{abstract}
By analyzing two waves of personal networks of immigrants to Catalonia (Spain) with a period of 1.5-2 years in between, a general model of change resulting from migration is proposed and people explanations that account for the observed changes are coded.
\end{abstract}

The analyzed communities are Argentineans $(n=25)$, Dominicans $(n=16)$, Moroccans $(n=13)$, and persons from Senegal and Gambia $(n=13)$. It turns out that getting a job and the participation in courses and team sport pushes for change that follows the proposed general model (evolution). In contrast, marrying a partner of the same origin, getting children, participating in an ethnic association, traveling to the country of origin, and being visited by kin and friends frequently leads to change in the opposite direction (involution). The use of metavisualizations of personal networks facilitates the comparison of networks of the same individual at different time points, as well as the comparison of networks aggregated over different communities. This aggregation shows that each of the four communities exhibits different ways of adaptation and change.

Key words: dynamic network analysis - personal networks - migration - mixed methods - social network analysis - visualization.

\footnotetext{
${ }^{1}$ Grupo de investigación EgoLab (www.egoredes.net), Departament d'Antropologia social i cultural UAB. Enviar correspondencia a: joseluis.molina@uab.es

2 Department of Computer \& Information Science, University of Konstanz. lerner@inf.uni-konstanz.de.

3 Grupo de investigación EgoLab, Departament d'Antropologia social i cultural - UAB. Silvia.gomez@uab.cat.
} 


\section{Las redes personales desde un punto de vista teórico ${ }^{4}$}

Las redes personales son el resultado de las fuerzas que reproducen la sociedad: la organización social y económica, las instituciones culturales y las acciones intencionadas y los resultados (previstos o no) de sus individuos (Giddens 1967, 1987). Su composición, estructura y patrón de cambio nos revelan tanto las posiciones ocupadas en esa organización económica y social, como el alcance de la influencia de instituciones culturales, el espacio de creación de cada individuo y las dinámicas emergentes debidas al azar o la transitividad en las relaciones. Por supuesto, estas redes sociales no sólo se explican sincrónicamente sino diácronicamente, como el resultado agregado de la Historia, que determina los grandes rasgos socioeconómicos y culturales de las sociedades en cuestión.

Además, los individuos no constituyen esferas independientes en estas redes que reciben y construyen de forma competente, sino que su conducta y sus cogniciones (por no hablar de la salud, por ejemplo) está también relacionada, aunque sea de un modo que todavía tenemos que clasificar de general.

Pensemos un momento en la composición de estas redes personales, es decir, en la distribución de las características de las personas que las componen. El porcentaje de hombres y/o mujeres, el porcentaje de personas de un grupo "étnico", el porcentaje de "familiares", la distribución geográfica de las personas conocidas, por ejemplo, nos informan sobre los roles ocupados por esa persona en la estructura social. Una persona con un cargo institucional, por ejemplo, tiene una composición diferente en su red que una trabajadora doméstica. Y así sucesivamente. Llamamos alteri al conjunto de personas que componen la red personal de ego.

Por otra parte, los alteri se relacionan también entre sí. Llamamos estructura a este conjunto de relaciones que podemos medir de forma precisa. Podemos saber si se relacionan todas esas personas en un solo grupo o en varios, a través de qué personas se conectan y si hay personas que no conocen al resto. La estructura es muy informativa sobre el capital social disponible de una persona (ver por ejemplo Burt 2002) y, en general, sobre la diversidad de espacios sociales en los que interactúa.

\footnotetext{
4 En esta introducción utilizamos "redes personales" y "redes sociales" en un sentido amplio, como sinónimos. Para una descripción detallada del concepto e historia de red personal ver Molina 2005.
} 
Composición y estructura reflejan un momento dado en la vida de una persona con determinados roles en la estructura socio-económica, en el marco de un conjunto de instituciones culturales y en un momento histórico determinado. Ahora bien, esta composición y estructura cambian constantemente. Algunos cambios son coyunturales como veremos más adelante mientras que otros son irreversibles o duraderos, como los derivados del ciclo vital o de la reproducción material de la vida.

Estudiando la composición, estructura y el patrón de cambio podemos interpretar mejor la proporción de fuerzas que, actuando simultáneamente, hacen de cada red personal un resultado único $\mathrm{y}$, al mismo tiempo, comprensible.

La tarea es compleja, pues el cambio no afecta solamente a los condicionantes y las iniciativas de los individuos estudiados, sino que simultáneamente afecta también a los alteri con los que se relacionan. Un cambio en una red personal afecta de diferentes modos a los alteri y viceversa, cambios en los alteri (esto es, en otras redes personales) afectan a ego. La muerte de un familiar, el cambio de residencia de un contacto, un matrimonio de un conocido o una separación, tiene efectos dispersos y diversos en estas estructuras locales de relaciones que llamamos redes sociales.

Así pues, desde un punto de vista de la teoría social, estudiando las redes sociales nos situamos en una perspectiva meso (Ferrand 2002; de Federico 2002) que permite por una parte estudiar los acontecimientos y las relaciones cotidianas de las vidas de las personas teniendo en cuenta sus universos de significados (micro) $y$, por otra, valorar los condicionantes macroestructurales de sus vidas al tener en cuenta sus posiciones en la estructura socioeconómica y los entramados institucionales en los que se desenvuelven.

Queremos destacar que este análisis es simultáneo pues los efectos de arriba-abajo (desde las instituciones o los individuos) y los de abajo-arriba (los cambios provocados por los individuos en la estructura social) se recogen o imprimen en las redes sociales que medimos con indicadores de composición, estructura y cambio. Como hemos dicho al comienzo, estas nuevas redes posibilitan nuevas acciones de reproducción y cambio de la estructura social (Cf. Bourdieu 1977; Coleman 1990). 
Además, este análisis incorpora también simultáneamente dimensiones cualitativas y cuantitativas, pues a las mediciones disponibles se añaden las interpretaciones que los mismos protagonistas hacen de su mundo social y de los cambios observados. En general, los individuos explican con competencia las razones de los cambios y se reconocen en las representaciones visuales que hacemos de sus vidas.

Este artículo se ocupa pues de identificar los factores que explican el cambio en las redes personales cualquiera que sea su naturaleza institucional, emergente, planificada, vital o por azar. Para ello hemos analizado 60 entrevistas realizadas con emigrantes en Cataluña entre un año y medio y dos años después de haber recogido sus redes personales y haberles entrevistado por primera vez. En estas entrevistas les hemos interrogado sobre los cambios observados en sus redes personales en ese período y las razones aducidas para explicar esos cambios. En base a esa información y a la modelización de sus redes personales proponemos un modelo de cambio general y las respectivas variaciones observadas en función de cada colectivo estudiado.

En el siguiente apartado describimos las características de los informantes y de la información recogida. A continuación nos ocuparemos de describir brevemente el método desarrollado para realizar meta-representaciones de las redes personales que permiten su comparación y agregación, para, finalmente, ocuparnos de presentar un sumario de las razones del cambio y una discusión de esta información.

\section{Estudio longitudinal de redes personales}

Durante los años 2004 al 2007, en el marco del proyecto financiado por la NSF ${ }^{5}$, Development of a Social Network Measure of Acculturation and its Application to Immigrant Populations in South Florida and Northeastern Spain, recogimos 300 redes personales en España (Cataluña) y 300 redes personales en Estados Unidos (Nueva York y Florida especialmente) de diferentes colectivos en ambos casos. Para ello utilizamos EgoNet $^{6}$, un programa que facilita la administración de un cuestionario sobre las características de ego y sus contactos y la posterior visualización y entrevista con los informantes acerca de sus redes personales.

\footnotetext{
${ }^{5}$ National Science Foundation, award no BCS-0417429, dirigido por Christopher McCarty en los Estados Unidos y José Luis Molina en España.
} 
A continuación, en el marco del proyecto financiado por la ESF y el MEC ${ }^{7}$ Dynamics of actors and networks across levels: individuals, groups, organizations and social settings ${ }^{8}$, se realizó una selección de casos para realizar una segunda entrevista intentando representar los diferentes tipos de redes personales identificadas (Lubbers et. al, 2006). Aunque la previsión inicial era realizar 90 entrevistas en la segunda oleada, la movilidad que caracteriza al colectivo de emigrantes, sobre todos aquéllos que se hayan en las primeras etapas, nos ha impedido cumplir este objetivo. En total hemos podido recoger 67 redes personales y entrevistar a 60 personas entre septiembre de 2007 y abril de 2008. La explicación de esta diferencia en el número de entrevistas y el número de redes es que normalmente son necesarias dos sesiones para completar el proceso: una primera para obtener la red personal y una segunda, días más tarde, para hacer la entrevista. Esta segunda parte no siempre se ha podido completar por varias razones, principalmente por falta de tiempo de las personas entrevistadas, a menudo con exigentes jornadas laborales. Las entrevistas fueran realizadas en su mayor parte por los mismos investigadores que en la primera ocasión, con lo que el contacto fue fácil y fluido. Estas entrevistas han sido de una hora aproximadamente de media. La distribución es la siguiente:

\begin{tabular}{|l|c|c|c|c|}
\hline \multicolumn{1}{|c|}{ Colectivo } & N & Edad media & $\begin{array}{c}\text { Media años } \\
\text { residencia }\end{array}$ & Sexos \\
\hline Argentina & 25 & 32 & 5 & 15 mujeres, 10 hombres \\
\hline Senegal y Gambia & 16 & 27 & 4 & Todos hombres \\
\hline $\begin{array}{l}\text { República } \\
\text { Dominicana }\end{array}$ & 13 & 36,2 & 6,5 & 3 mujeres, 10 hombres \\
\hline Marruecos & 13 & 32,7 & 12 & 6 mujeres, 7 hombres \\
\hline \multicolumn{1}{|c|}{ Total } & $\mathbf{6 7}$ & $\mathbf{3 2}$ & $\mathbf{6 , 4}$ & $\begin{array}{c}\mathbf{2 4} \text { mujeres, } \mathbf{4 3} \\
\text { hombres }\end{array}$ \\
\hline
\end{tabular}

Tabla 1. Distribución de las redes personales recogidas en la segunda oleada

Las entrevistas con personas procedentes de Argentina se han realizado en Barcelona, Vic y otras localidades cercanas a Vic. Las entrevistas con personas de

\footnotetext{
6 La última versión de EgoNet está disponible de forma gratuita en Sourceforge http://sourceforge. net/projects/egonet/.

${ }^{7}$ El European Collaborative Research Project (ECRP) financiado por la European Science Foundation y el Ministerio de Ciencia y Tecnología (SEJ 2005-25683-E, SEJ 2007-29468-E, 05 ECRP_FP026) en el caso español, dispone de un equipo central centrado en la metodología para la modelización del cambio (Tom Snijders coordina el proyecto europeo y dirige el equipo que desarrolla SIENA http://stat.gamma.rug. $\mathrm{nl} /$ siena.html) y otro equipo centrado en la visualización (Ulrik Brandes dirige el equipo que desarrolla visone http://visone.info/). El resto de equipos, como el español, codirigido por José Luis Molina (UAB), I sidro Maya Jariego (US) y Carlos Lozares (UAB, se ocupa de estudiar casos sustantivos en cada país.

${ }^{8}$ http://stat. gamma.rug. nl/ECRP-DANL/default.htm
} 
Senegal y Gambia se han realizado en Mataró (diola, mandinga, wolof, bambara). Las entrevistas con personas de la República Dominicana se han realizado en Hospitalet y, finalmente, las entrevistas con personas marroquíes (amazig) se han realizado también en Vic y localidades próximas.

El método seguido para la segunda oleada ha sido el siguiente9:

1. El entrevistador/a imprime una copia de la red personal de la persona que va a entrevistar (la red de la primera oleada).

2. Una vez ha recogido los datos descriptivos complementarios de la persona entrevistada, le pide una lista de 45 contactos activos mediante un generador de nombres abierto:

Por favor, escriba una lista de 45 personas que Usted conozca por su nombre y viceversa. Puede ser cualquier persona. Intente incluir gente que sea próxima e importante para Usted. También puede incluir personas que pueden no ser tan cercanas pero que acostumbra a ver mucho. Puede ayudarle pensar en diferentes grupos de personas en diferentes lugares. Escriba el nombre y el apellido de forma abreviada para que solamente Usted pueda reconocer a las personas. Es importante que no abrevie demasiado para poder reconocerlas más tarde. Por ejemplo: Mig Cervan por "Miguel de Cervantes"

Este generador de nombres tiene la ventaja que permite recoger tanto lazos fuertes como lazos débiles. Para una justificación de la metodología y una discusión de los sesgos cognitivos ver McCarty (2002, 2007) y Molina (2007) respectivamente.

3. A continuación entrevistador y entrevistado comparan conjuntamente las dos listas de personas y completan la variable "repetido" con "sí" o "no" para cada alter de la segunda oleada.

4. Una vez identificado cada alter con esta variable, se continúa con el cuestionario, recogiendo datos sobre cada uno de los alteri y sus relaciones entre sí.

5. Por último, una vez completado el cuestionario se visualiza la red y se interroga a la persona entrevistada acerca de los cambios percibidos

9 Agradecemos a Joan Miquel Verd (Sociología, UAB), miembro del equipo del proyecto ECRP su participación en la elaboración de esta metodología. 
personas, grupos, estructura, composición, así como a nivel personal en la identificación étnica.

Este método tiene la ventaja que recoge de una forma solvente el mundo social que rodea a cada ego en todas sus dimensiones institucionales. Desde un punto de vista cognitivo, la memoria acerca de las relaciones sociales está organizada en gran parte por contextos de interacción, seguramente debido a que recordamos eventos conexos en el tiempo o en el espacio. Al ser la lista lo suficientemente larga, los entrevistados recuerdan en primer lugar lazos fuertes, normalmente familiares y después se ven obligados a cambiar de contexto institucional (por ejemplo, lugar de trabajo) en el que recuerdan por asociación una serie de personas y después a otro (por ejemplo, deporte u ocio) y así sucesivamente.

Un ejemplo de visualizaciones de informantes tomadas al azar de cada colectivo se puede ver en la siguiente ilustración.

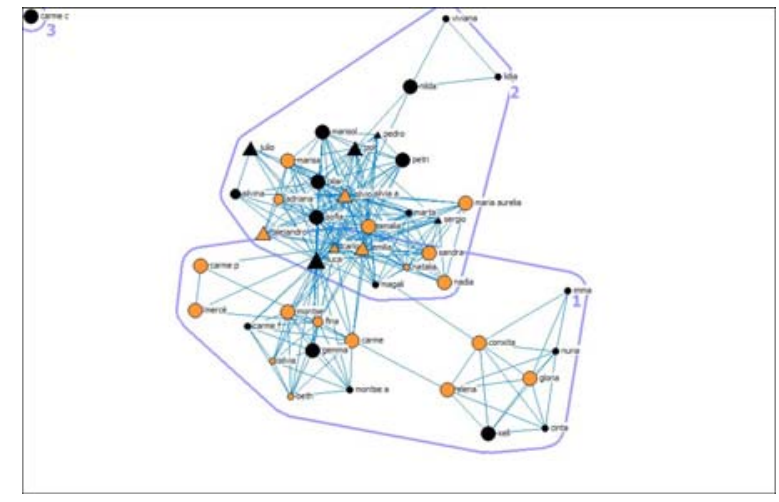

Mujer argentina

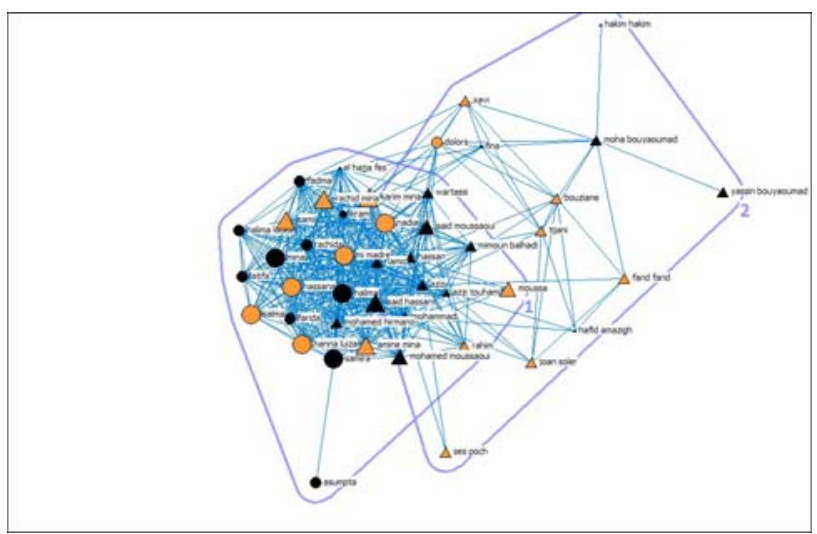

Hombre Marroquí (amazig)

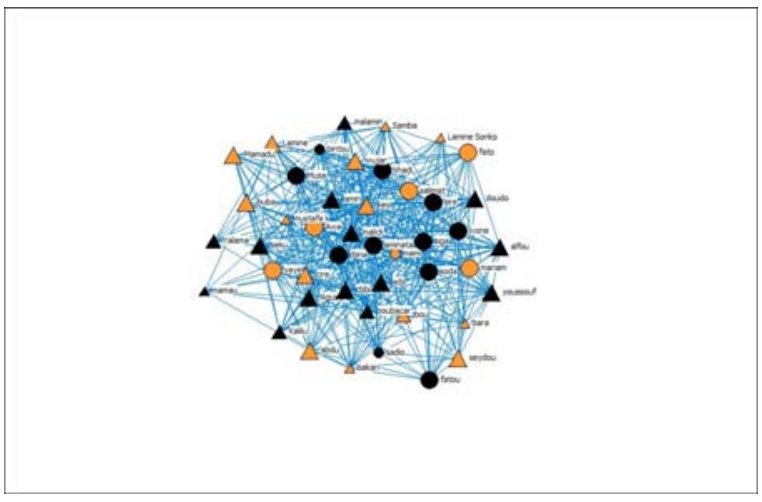

Hombre Senegal (mandinga)

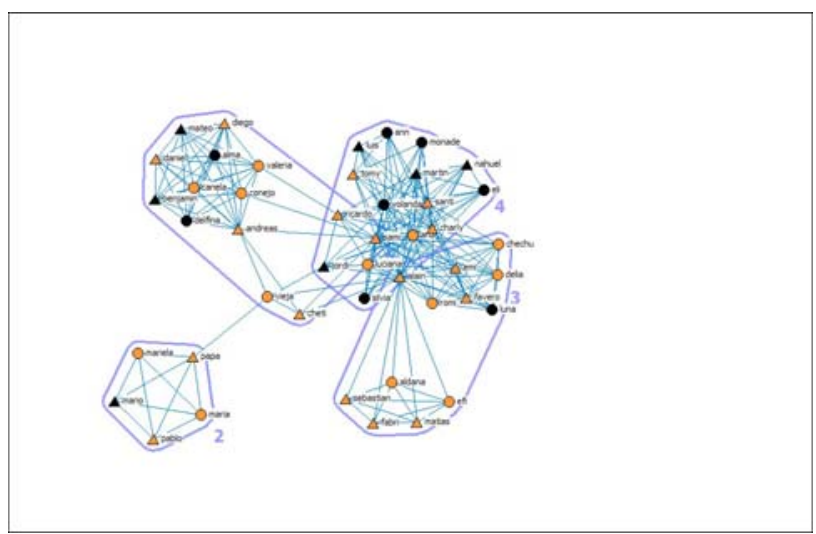

Hombre Dominicano 
I lustración 1. Visualizaciones de redes personales. En negro las personas nominadas por primera vez en la segunda oleada.

La desventaja de este método es que es muy largo de llevar a cabo ( jla persona entrevistada tiene que evaluar 990 posibilidades de interacción!) y, por otra parte, que es muy sensible a la frecuencia de interacción. Efectivamente, recientes episodios en la vida del entrevistado como viajes o visitas de familiares quedan reflejados en sus redes aunque posiblemente se trate de efectos coyunturales y en unos pocos meses, esas personas pasen de ser contactos activos y funcionales a contactos latentes.

Por otra parte, a pesar de que las visualizaciones ${ }^{10}$ nos permiten realizar una investigación exhaustiva de cada caso pues podemos identificar grupos y combinar las variables visuales de tamaño, forma, posición, etiqueta y color para mostrar simultáneamente variables como la proximidad percibida, el sexo, el lugar de residencia y la nacionalidad, por ejemplo, son difíciles de comparar entre sí y con otras redes de otras personas. Para ello, hemos utilizado un método que permite obtener de cada red personal obtenida una metarepresentación susceptible de ser agregada o comparada con otras.

\section{Metarepresentaciones de las redes personales}

Con el objetivo de poder comparar las redes personales obtenidas en las mencionadas investigaciones, se ha desarrollado el método de clustered graphs (Brandes et. al. 2008; ver también Lerner et. al. 2007 y 2008) consistente en representar una selección de variables de composición y estructura mediante variaciones de un esquema fijo.

Así en la llustración 2 se puede ver el modelo base un ejemplo de aplicación. En él se representan tanto el número de personas en cada una de las clases o tipos seleccionados (mediante el tamaño de los círculos) la densidad de relaciones intragrupos (mediante la gradación de grises) y la densidad de relaciones intergrupos (mediante el grosor de las líneas).

\footnotetext{
10 Para una discusión de los efectos de la visualización de sus redes personales en los informantes ver Maya Jariego et al. 2005.
} 

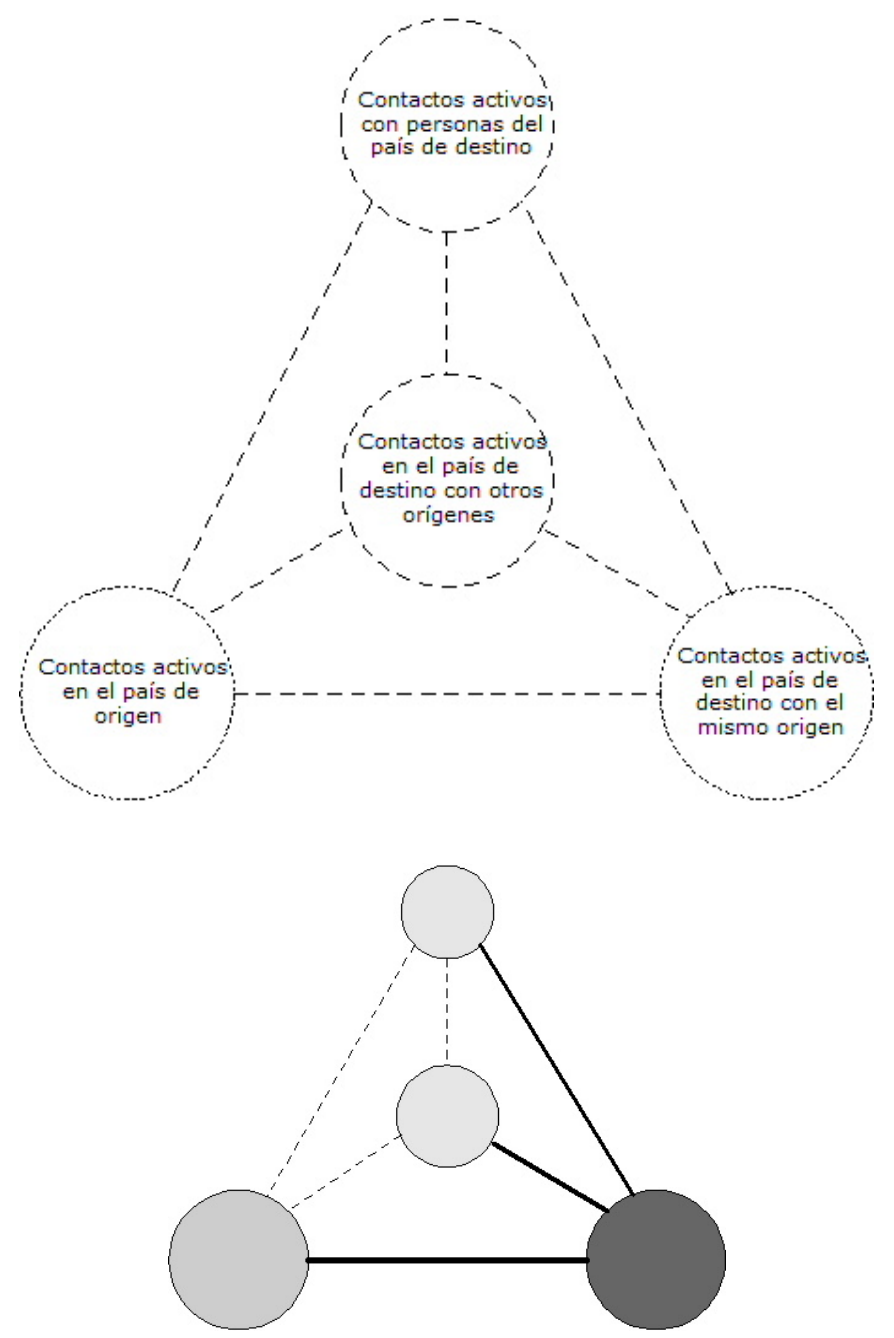

I lustración 2. Modelo base para la comparación (arriba) y un ejemplo de aplicación (abajo).

Así podemos interpretar que en este caso la persona en cuestión dispone de una red con muchas personas en origen pero que tienen pocas relaciones entre sí (gris claro), muchas personas también en destino muy relacionadas entre sí (gris oscuro), algunas personas conocidas en destino con otros orígenes (menor tamaño del círculo central y color gris claro) y algunas personas también del país de destino que tampoco tienen muchas relaciones entre sí. I gualmente, el gráfico nos muestra que hay relaciones entre personas del país de origen y personas de ese mismo origen en el país de destino y algunas relaciones con estas últimas con los otros dos tipos de personas. También es evidente que no hay relaciones entre personas del país de origen y personas que tienen la residencia en el país de destino excepto en el caso ya señalado. 
Por lo tanto podemos representar cada red personal con un gráfico de estas características y compararla bien con una red de la misma persona en otro momento, bien con la red de otras personas. En este caso, para interpretar cada una de las entrevistas se ha dispuesto además de la grabación y de los datos descriptivos de las personas entrevistadas, la red personal tal como la muestra Egonet (ver Ilustración 1) y dos gráficos por persona correspondientes a las dos oleadas (ver Ilustración 3).
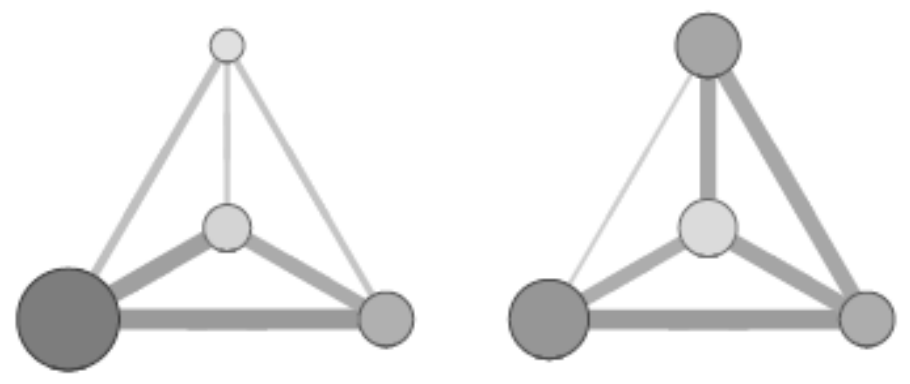

I lustración 3. Metarepresentaciones de la red de la primera oleada (izquierda) y de la segunda oleada (derecha) de una misma persona

De esta forma es posible, junto con la visualización de la red personal que muestra todos los detalles de cada caso, observar fácilmente los cambios observados. En el ejemplo de la Ilustración podemos ver cómo la proporción de personas en el país de origen se reduce en la segunda oleada, así como aumentan las personas con otros orígenes y los "nativos" y sus relaciones internas. A través de la entrevista grabada ha sido posible escuchar las razones aducidas para explicar esos cambios.

Estas metarepresentaciones tienen la ventaja de retener gran parte de la complejidad de las redes personales y, al mismo tiempo, reflejar de una forma más estable los cambios observados. Así por ejemplo se puede observar un cambio en la estructura general representada en la Ilustración 3, pero este cambio es mucho más marcado en la red personal correspondiente representada en la llustración 4, donde se representa en color negro las personas nuevas en la red ( ¡25 sobre 45!). 


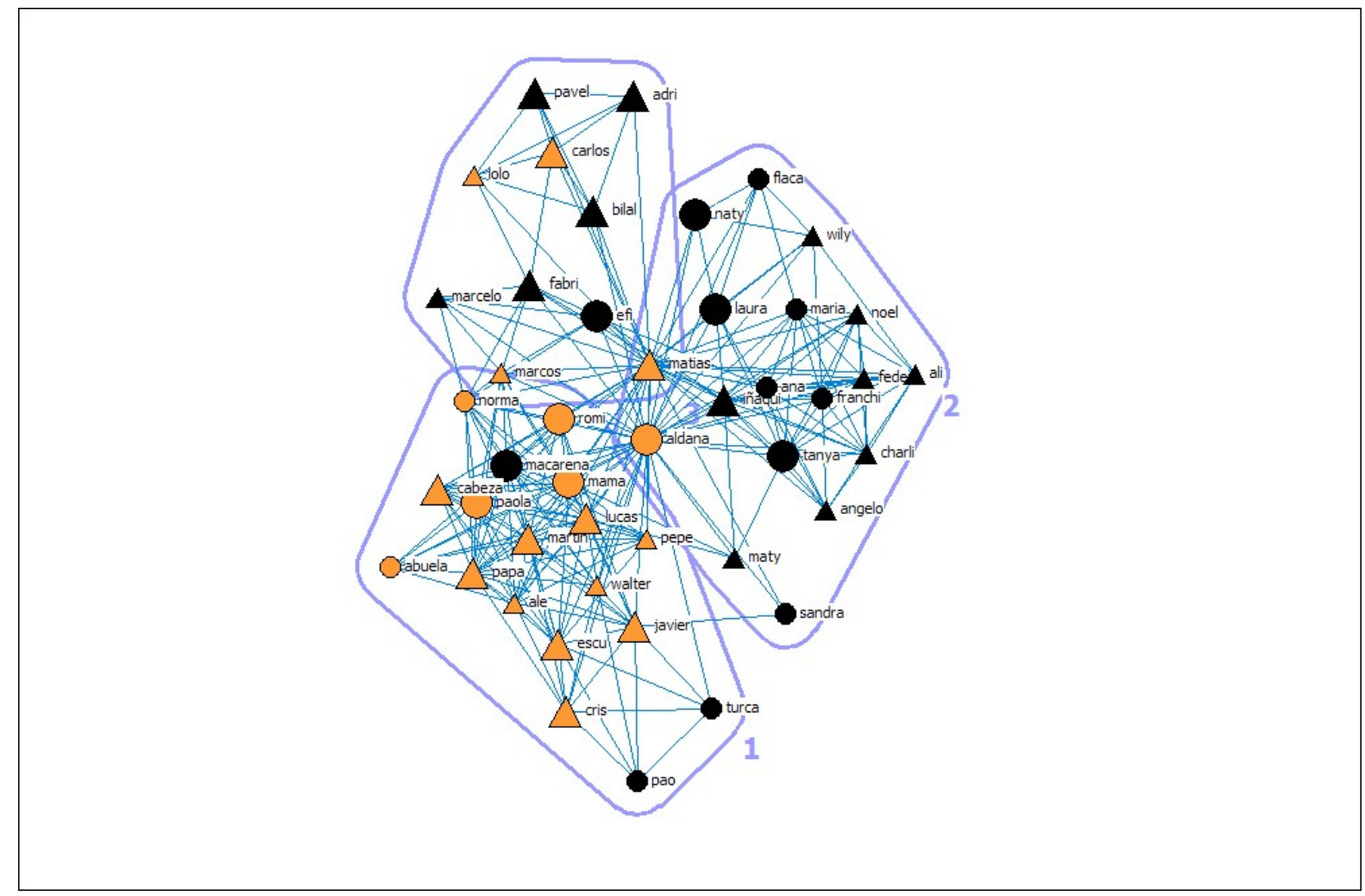

I lustración 4. Red personal de la segunda oleada. En negro las personas nominadas por primera vez.

En el caso de las personas inmigrantes el ritmo de cambio es especialmente rápido, sobre todo al inicio del proceso y dependiendo de las características del contexto de recepción y las oportunidades para interactuar con personas de origen diferente. También las redes reconstruidas en destino son más volátiles y muy dependientes de los contextos de interacción y de los medios de comunicación, por lo que la pérdida de un teléfono móvil o un cambio de residencia pueden acabar, o de hecho acaban, con relaciones recién iniciadas o recuperadas.

Pero no solamente cambian las redes personales en destino, también lo hacen en origen. Personas con las que no se tenía contacto en origen inician su acercamiento a las personas emigradas para intentar obtener soporte o iniciar una relación que ahora es más atractiva. I gualmente, los contactos reactivados o iniciados en destino (alteri) tienen sus propias redes en origen que acaban iniciando nuevos contactos con ego.

Por último, la situación se completa con el hecho de que no existe un único destino, incluso en el seno de un mismo grupo familiar, sino varios, con lo que las redes y sus dinámicas asociadas se reparten entre diferentes países. 
Veamos a continuación cómo cambian estas redes. Analizaremos en primer lugar el cambio de larga duración basado en un modelo teórico y en segundo lugar el cambio en el corto plazo, a partir de los datos disponibles.

\section{Patrones de cambio de inmigrantes en Cataluña}

Desde un punto de vista teórico, podemos modelar el cambio en un proceso migratorio de la forma siguiente: una primera fase sin contactos en destino, una segunda fase transnacional con algunas relaciones con otros colectivos, una tercera fase de acomodación en la sociedad de destino junto con una selección de las relaciones a mantener en origen (normalmente lazos fuertes familiares) y, finalmente, una fase de asimilación con segundas o terceras generaciones.

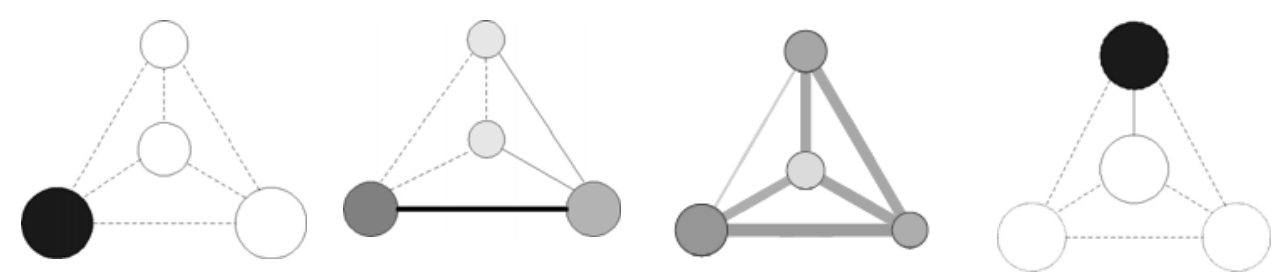

llustración 5. Modelo general de cambio

Este modelo general de cambio asume que es posible la interacción entre personas de diferentes grupos y que existen espacios institucionales que la permiten.

Por supuesto, existen escenarios alternativos al modelo que acabamos de exponer, ya sean transitorios o estables. En general podemos clasificar en cuatro tipos ideales las modalidades de adaptación de las personas que realizan un proceso migratorio (Ilustración 6, Cf. Berry, 2003; Portes et. al. 1986): Tipo I - Asimilación, Tipo II - Enclave étnico, Tipo III - Red transnacional y lo que hemos Ilamado, a falta de una mejor denominación, Tipo IV - "Red múltiple".

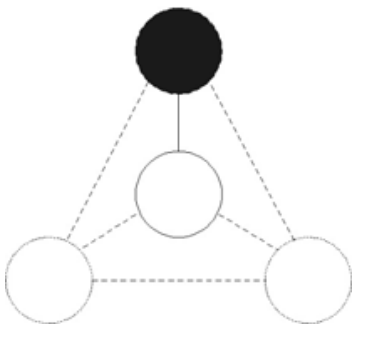

Tipo I - Asimilación

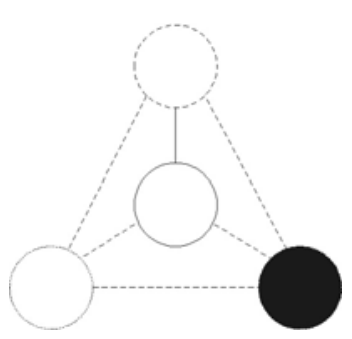

Tipo II - Enclave étnico 


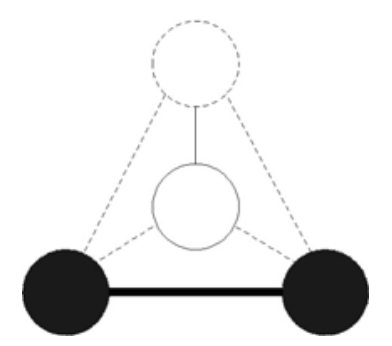

Tipo I I I - Red transnacional

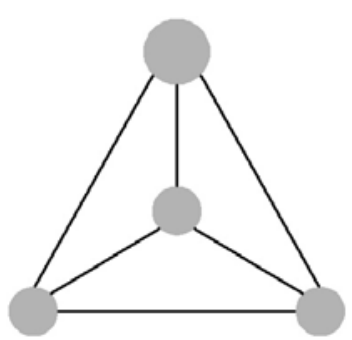

Tipo IV - Red múltiple

I lustración 6. Tipos ideales de redes personales de emigrantes.

Aunque es posible encontrar en nuestros datos ejemplos de cada tipo, en general podemos decir que las redes recogidas en esta investigación se sitúan en los tipos III-IV.

Por ejemplo, para el Tipo III-IV podemos observar las colecciones de metarepresentaciones de las redes personales de las personas de Gambia y Senegal entrevistadas (Ilustración 7), de República Dominicana (Ilustración 8) y de Marruecos (Ilustración 9), mientras que para el tipo IV podemos ver el caso de las personas de Argentina (Ilustración 10).

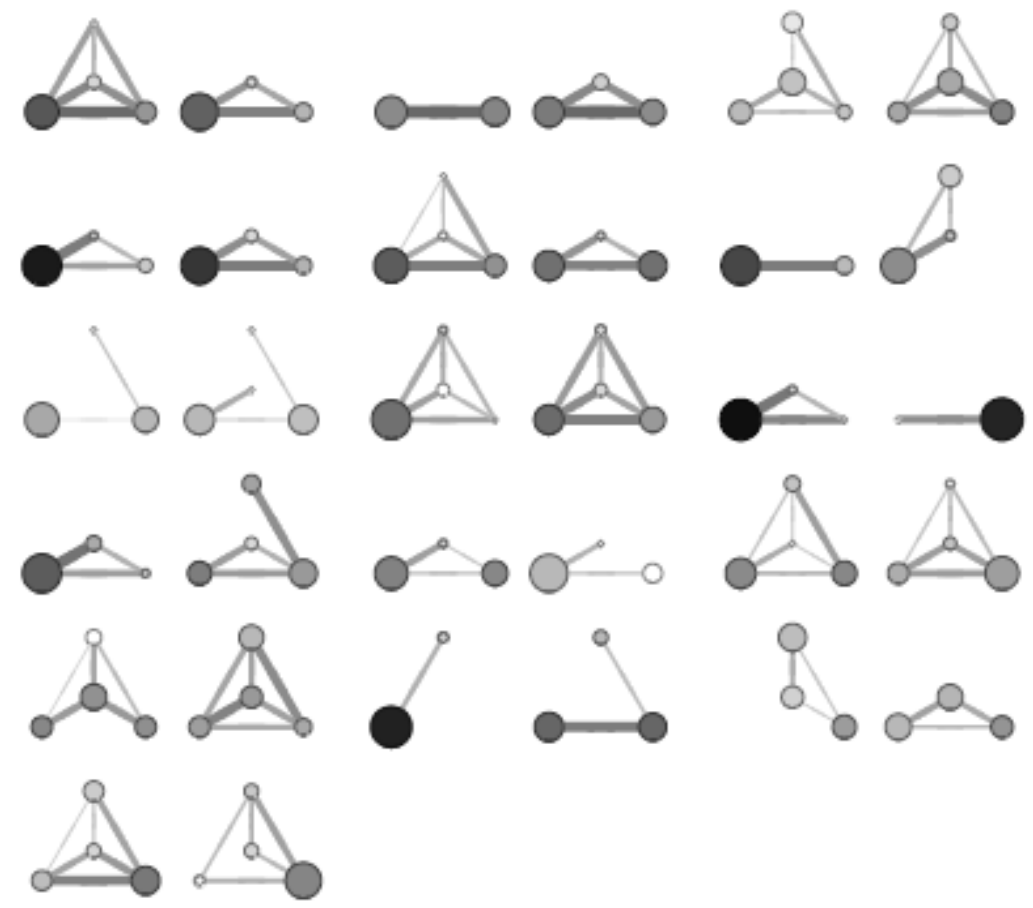

I lustración 7. Pares de metarepresentaciones de las redes personales de personas de Gambia y Senegal ordenadas de menos a más tiempo de residencia. 

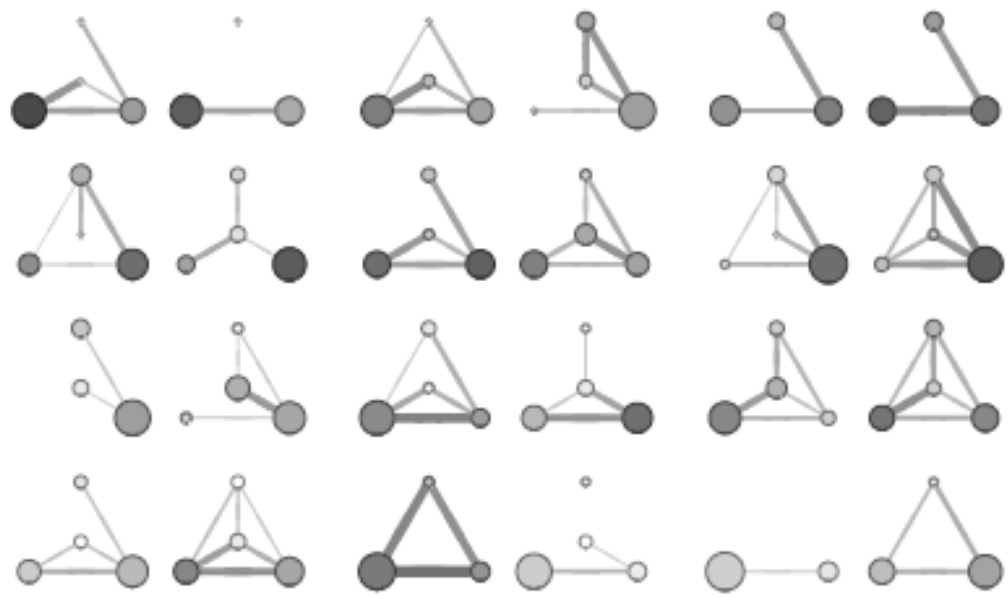

I lustración 8. Pares de metarepresentaciones de las redes personales de personas de República Dominicana ordenadas de menos a más tiempo de residencia.
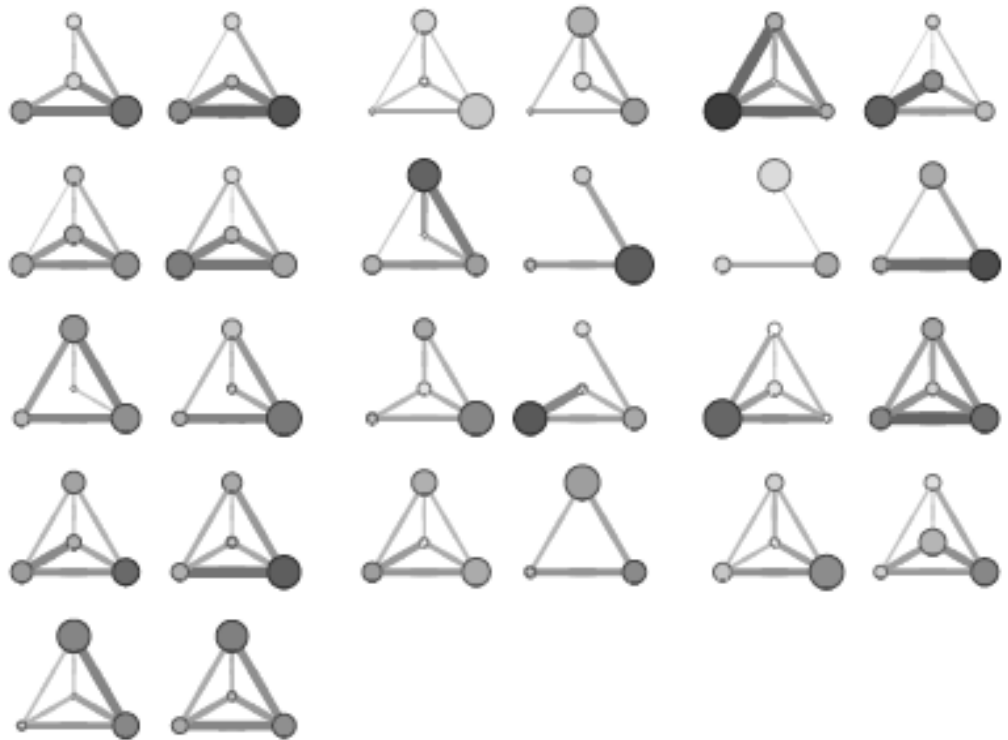

I lustración 9. Pares de metarepresentaciones de las redes personales de personas de Marruecos ordenadas de menos a más tiempo de residencia. 

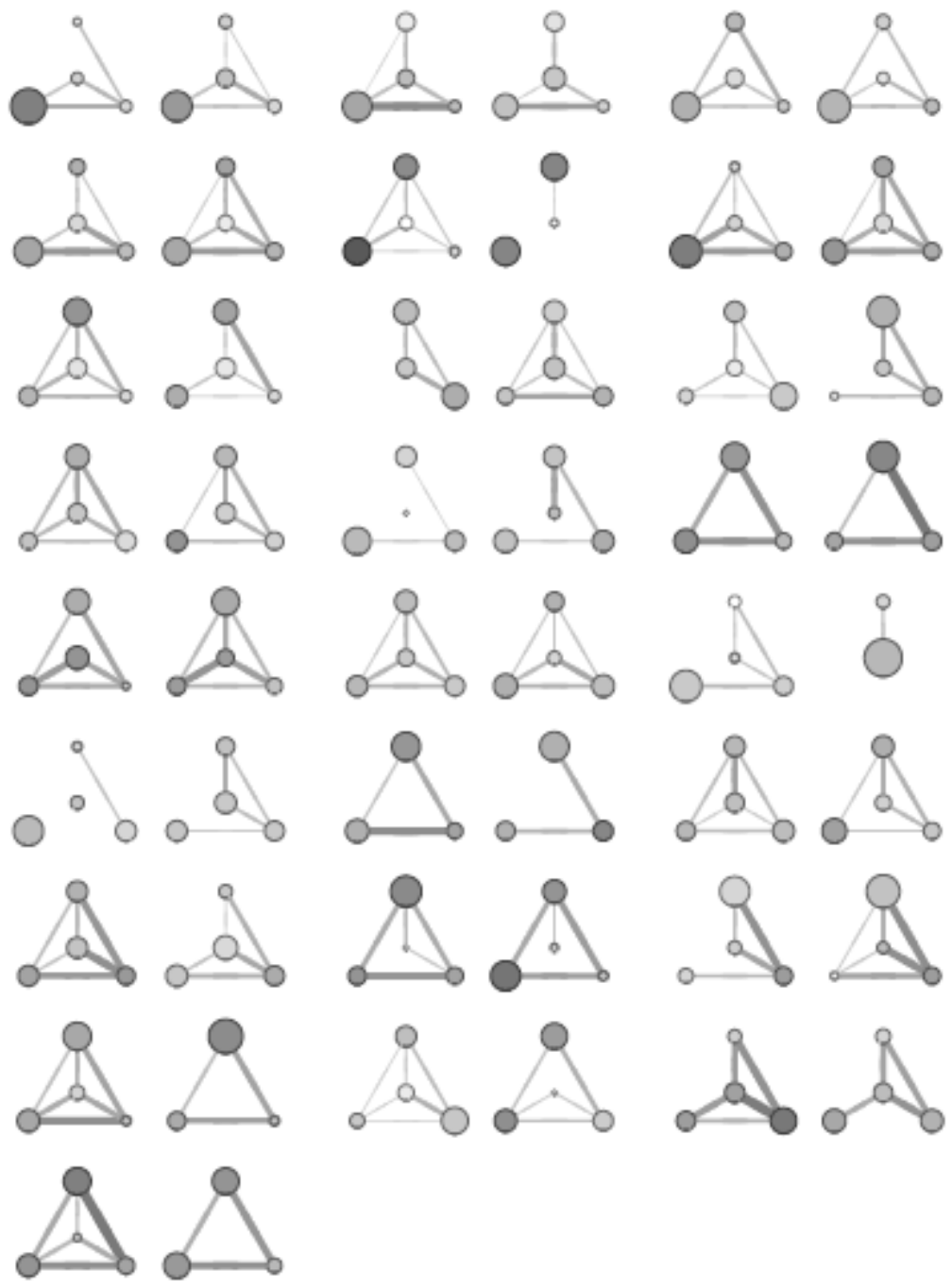

I lustración 10. Pares de metarepresentaciones de las redes personales de personas de Argentina ordenadas de menos a más tiempo de residencia.

Pero una manera más efectiva de poder analizar el tipo de cambio de estas colecciones de redes personales es agregando las redes de cada colectivo según el método desarrollado por Brandes et. al. (2008). En la Ilustración 11 podemos ver cómo en el caso de personas de Argentina, la proporción de "nativos" es más alta que el resto de colectivos, incluido el marroquí, con una trayectoria de inmigración mucho más larga. En poco tiempo exhiben un modelo de acomodación de Tipo IV.

El caso de las personas de Marruecos es peculiar porque parece haber una “involución" del Tipo IV al Tipo III, que estudiaremos más adelante. Por lo que se refiere a las personas de la República Dominicana la tendencia parece ir más a una mezcla del modelo de "enclave étnico" (Tipo II) y transnacional (Tipo III), mientras que las personas de Senegal y Gambia, con la trayectoria más reciente de 
emigración, exhiben un Tipo III de red transnacional complementado con personas de otros orígenes.
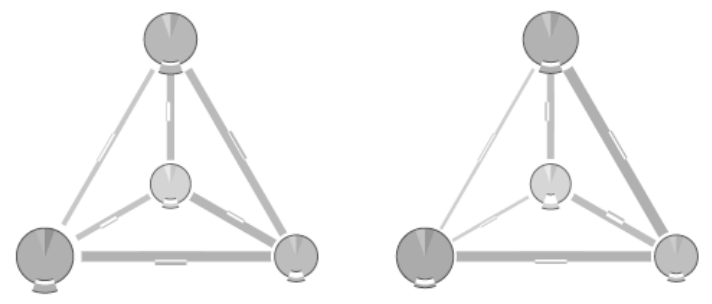

Argentina $(n=25)$
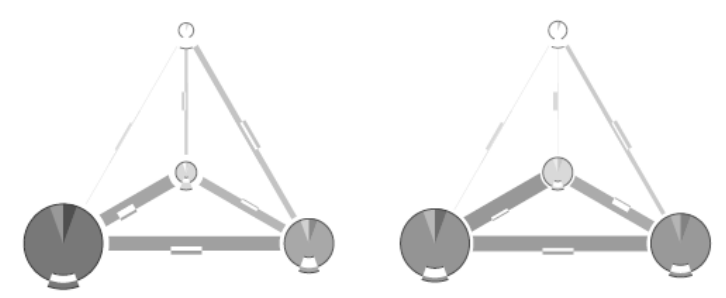

Senegal y Gambia $(n=16)$
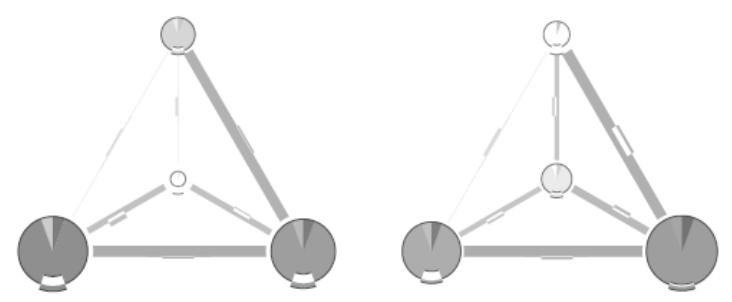

República Dominicana $(n=13)$
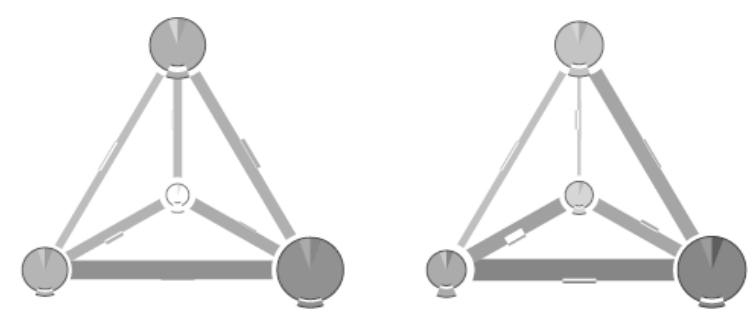

Marruecos $(n=13)$

I lustración 11. Metarepresentaciones de las redes personales agregadas por colectivos.

Pasamos ahora a describir las razones aducidas para explicar los cambios observados en las redes personales de las personas entrevistadas.

\section{El cambio en el corto plazo}

En el intervalo entre un año y medio y dos años se han producido muchos cambios en las redes personales de las personas entrevistadas. Algunos de estos cambios han permitido conocer personas nuevas de características diferentes que hacen avanzar la red personal en la línea del patrón de cambio de la Ilustración 5. Llamamos a esos cambios, evolución. Por otra parte, otros cambios han ido en la dirección contraria, es decir en la línea de aumentar la homogeneidad de los tipos de contactos de personas del mismo origen. Llamamos a esos cambios involución. Por último, también hay cambios que no modifican las características generales de las redes personales (por ejemplo la sustitución de personas por otras que siguen ostentando los mismos roles) o que, en función de las circunstancias, pueden llevar en una u otra dirección. 
Veamos un ejemplo de evolución fuerte y otro de involución fuerte para poder interpretar mejor la información expuesta (Ilustración 12).
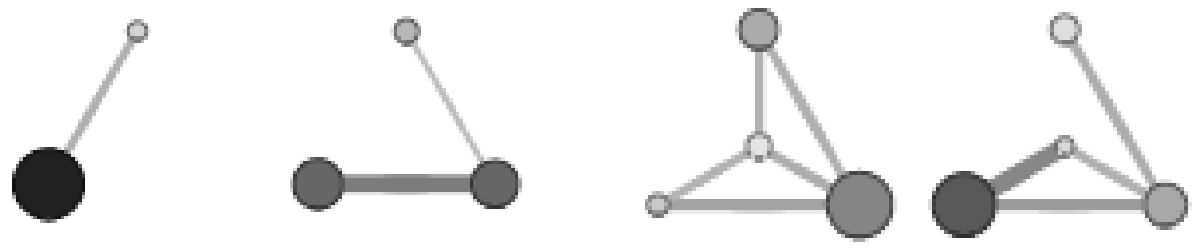

I lustración 12. Ejemplo de evolución fuerte (izquierda) y de involución fuerte (derecha).

En el par de la izquierda podemos ver una primera fase con personas en origen muy conectadas entre ellas y un contacto con algunas personas del país de destino, una relación de trabajo en este caso. Al cabo de un tiempo, la red ha evolucionado a una estructura transnacional con más "nativos" en la red ("evolución fuerte").

En el par de la derecha podemos ver cómo el número y la densidad de relaciones de las personas "nativas" decrecen en la segunda oleada y cómo la comunidad de origen se constituye como la principal fuente de contacto, sustituyendo a la propia comunidad emigrada ("involución fuerte").

En la Tabla 2 se puede observar la distribución de las razones aducidas para explicar estos cambios. Estas razones han sido codificadas en 8 tipos que describimos a continuación.

\begin{tabular}{|l|c|c|}
\hline \multicolumn{1}{|c|}{ Razones } & N & \% \\
\hline 1 Trabajo-residencia & 63 & 30 \\
\hline 2 Espacios de interacción & 44 & 21 \\
\hline 3 Ciclo vital & 25 & 12 \\
\hline 4 Transitividad & 24 & 12 \\
\hline 5 Movilidad & 23 & 11 \\
\hline 6 Error & 13 & 6 \\
\hline 7 Limitación 45 & 11 & 5 \\
\hline 8 Comunicación & 5 & 2 \\
\hline \multicolumn{1}{|c|}{ Total } & $\mathbf{2 0 8}$ & $\mathbf{1 0 0}$ \\
\hline
\end{tabular}

Tabla 2. Codificación de las razones aducidas para el cambio

Pasemos a explicar cada una de ellas.

\section{Reproducción de la vida material}

En primer lugar nos encontramos con los lugares de trabajo y la residencia (tanto a nivel de vivienda, de vecinos y de localidad) como la principal razón que explica cambios en las redes personales. 
Trabajo. Normalmente, excepto en los casos de negocios familiares, la obtención de un trabajo implica la ampliación de las redes personales tanto de hombres como de mujeres, que interactúan con "nativos" y personas de otros orígenes. Se trataría de un factor de cambio evolutivo según nuestra terminología. Podemos calificar este factor de evolución fuerte.

Residencia. Por otra parte, la residencia suele comportar un aumento de la proporción de personas del mismo origen, bien por compartir piso, bien por obtener la vivienda a partir de la información proporcionada por éstos. También en la vivienda se producen visitas y eventos que aumentan la transitividad de las redes, aunque no necesariamente con personas del mismo origen. En el caso de marroquíes en Vic y otras localidades, el papel de los vecinos es también importante, a menudo catalanes/españoles. Calificaremos este favor de involución media.

\section{Espacios de interacción}

El segundo tipo de razones aducidas para explicar los cambios han sido los espacios de interacción, entendiendo por tales cursos, asociaciones, discotecas, bares "étnicos", lugares de culto y espacios deportivos. Estos espacios tienen una gran importancia en la conformación de los patrones de cambio que pasamos a discutir a continuación.

Cursos. Los cursos representan un espacio privilegiado por la interacción con personas de otros orígenes. Cursos de enseñanza reglada, ocupacionales, de catalán y de educación general para adultos tienen, por este orden, un importante papel en la evolución de las redes personales que podemos calificar de evolución media-alta, según los casos. Por otra parte, el abandono de estos cursos o su finalización también representan una fuente de involución importante.

Asociaciones. Excepto para las personas que tienen un rol directivo en las asociaciones, las cuales se relacionan con Administraciones, sindicatos, ONGs y partidos políticos, según nuestra experiencia el efecto en las redes personales de las personas que las componen es involutivo, en el sentido de aumentar la homogeneidad y el porcentaje de las personas con el mismo origen. Esto es especialmente cierto en el caso de la asociación dominicana que gira en torno al softball, en la que la centralidad de los acontecimientos sociales y deportivos es importante. Calificamos de involución media-alta, según los casos, este factor de cambio. 
Discotecas. Excepto en el caso de las personas dominicanas que han mencionado esta cuestión (y dada la centralidad de la música dominicana en su cultura) en el resto de casos las discotecas y los festivales de música pueden ser lugares de contacto de nuevas personas para los jóvenes, a menudo del sexo contrario, objetivo específico de estos espacios. Podemos calificar en general esta razón de evolución baja.

Bares "étnicos". Especialmente en caso de dominicanos y hombres marroquíes, este espacio ha sido aducido para explicar cambios que podemos calificar de involución media-baja.

Espacios de culto. Las personas entrevistadas han citado solamente en algunas ocasiones los espacios de culto como explicaciones de cambios en las redes. Se ha tratado de personas de origen marroquí. Involución baja.

Deporte. Excepto en el caso que el deporte sea "étnico" (como el softball) y/o organizado por una asociación, las actividades deportivas (fútbol y baloncesto) se han revelado como una fuente de contactos heterófilos. Por lo tanto, diferenciamos el deporte étnicamente dirigido (involución media-alta) y el deporte heterófilo (evolución baja), aquél realizado en canchas o campos de juego entre personas que no se conocen previamente. Excepto en el caso de los jóvenes y de las actividades étnicamente organizadas, las oportunidades para hacer deporte son bajas por la presión laboral que soportan estas personas, por lo que no se puede esperar que el deporte sea una fuente muy grande de contactos, aunque en los casos que se ha mencionado este factor sí ha tenido cierta importancia.

\section{Ciclo vital}

El ciclo vital lo constituyen los acontecimientos relacionados con el matrimonio, con personas del mismo origen o con personas de otros orígenes, con el nacimiento de hijos, sobrinos, nietos y también con la muerte de personas queridas o importantes.

Matrimonio. En general, el matrimonio, ya sea con personas del mismo grupo o con personas de otros grupos (hemos encontrado varios casos de matrimonios entre personas argentinas y españoles) implica una reactivación de las relaciones familiares, primero con la familia propia y después, en menor medida, con la familia política. Además de la ceremonia de la boda, el matrimonio implica a menudo viajes y visitas de familiares, con lo se produce un efecto involutivo fuerte, compensado solamente en parte con la familia política en el caso de matrimonios entre personas 
de nacionalidades diferentes. Esto es especialmente cierto en el caso de las personas marroquíes casadas recientemente, dándose el caso que en su mayor parte uno de los cónyuges procede de Marruecos y tiene allí la mayor parte o toda su familia, renovando la cadena migratoria. Esto explica que a pesar de tener una larga trayectoria de inmigración en Cataluña, las redes personales de este colectivo presenten una fuerte proporción de personas con el mismo origen, incluso en el caso de jóvenes de segunda generación. De alguna forma la tendencia al Tipo IV se compensa con matrimonios con personas cuyas familias se hayan en una fase menos evolucionada de la cadena migratoria, presentando características también del Tipo II (ver la llustración 6).

En conjunto pues, calificamos de efecto evolutivo medio los matrimonios heterófilos (personas de distintos orígenes) y de involutivo fuerte los matrimonios homófilos (personas con el mismo origen).

Separaciones y divorcios. Los importantes efectos de las separaciones y divorcios en las redes personales son bien conocidos (Terhell et al., 2004, 2007). Los cónyuges llevan a la pareja sus redes personales, las cuales presentan un grado de solape al inicio y evolucionan en el sentido que la pareja se acaba situando en el centro de la red personal. Separaciones y divorcios implican la súbita desaparición de una parte de la red personal y la necesidad de reconstruir una nueva red de relaciones. En general, en los casos que se han producido separaciones y divorcios entre los dos momentos de las entrevistas el efecto ha sido involutivo medio, especialmente si la pareja era española.

Nacimiento. El nacimiento de nuevas personas implica un reforzamiento de las relaciones sociales preexistentes, especialmente las familiares, con lo que el efecto es también involutivo medio, incluso en el caso de parejas mixtas.

Muerte. La muerte de personas queridas implica también la desaparición de sus orígenes y referentes, con lo que si estas personas son padres y/o abuelos, el efecto es el fortalecimiento del núcleo familiar más cercano pero al mismo tiempo la desaparición de contactos relacionados con esa persona, con el lo que el resultado es un efecto evolutivo bajo.

\section{Transitividad}

Transitividad. Las relaciones que se establecen entre personas que tienen conocidos en común tienen un importante papel en el cambio observado, especialmente para la consecución de trabajos o en actividades de ocio. Es lógico que esta transitividad 
se produzca entre las personas con las que se tiene más oportunidad de interacción, es decir en la residencia y el trabajo, con efectos contrarios (más homófilos y más heterófilos respectivamente). Es decir, que la transitividad por sí misma no constituye un factor de cambio en una u otra dirección.

Conflictos. Podemos considerar los conflictos como un tipo de transitividad negativa. En algunos casos hemos observado la existencia de conflictos, normalmente entre personas del mismo origen que, lejos de ser coyunturales, se mantienen a través de los años. Al igual que en el caso de la transitividad, esas pérdidas de contactos no implican una dirección en el cambio observado. Las relaciones "negativas" es una de las cuestiones que precisan de un desarrollo teórico y metodológico para poder completar las descripciones que hacemos de las redes sociales.

\section{Movilidad}

Viajes. La movilidad constituye una característica estructural de nuestro tiempo. Las personas viajan mucho, por lo menos hasta ahora. Muchas de las personas que hemos entrevistado han recalado en Cataluña después de complicados itinerarios en otros países, países en los que mantienen algunos contactos activos. Los viajes, normalmente a los países de origen, implican por una parte una reactivación de contactos, normalmente coyuntural y por otra el mantenimiento de las relaciones fuertes. En conjunto podemos calificar que los viajes tienen un efecto de involución media.

Visitas. Por otra parte, las visitas de familiares y amigos, la contraparte de los viajes de ego, implican también una reactivación de los contactos con las personas que visitan y parte de sus propios contactos, especialmente las personas en común, por lo que se produce un fenómeno de involución baja.

\section{Error y limitación a 45 alteri}

Error. En algunos casos las personas se equivocaron al establecer relaciones o lugares de residencia de los alteri. En la mayor parte de los casos esos errores fueron detectados durante la entrevista y corregidos en el momento.

Limitación a 45 alteri. La limitación de 45 personas tampoco parece influir en la estructura de las relaciones reportadas por los informantes. Es decir que podemos encontrar a muchas personas nuevas de una oleada a la siguiente, pero con los mismos roles, con lo que de hecho se produce un efecto de reemplazamiento. 


\section{Medios de comunicación}

Móvil. El uso del teléfono móvil es omnipresente. Las entrevistas se veían a menudo interrumpidas por llamadas de amigos y familiares. La pérdida o el cambio de móvil suele implicar también la pérdida de lazos débiles grabados en la agenda. El móvil se utiliza para un primer contacto y después de recurre a un teléfono fijo o a un locutorio para hacer una llamada de más duración. Involución baja.

Messenger. Aunque la investigación no exploraba específicamente los medios de comunicación utilizados, en algunos casos nos encontramos con la cuestión, sobre todo en los más jóvenes, que no utilizar un tipo de tecnología como el "Messenger" provoca la pérdida de la relación y, viceversa, compartir tecnología (y seguramente empresa proveedora de servicios de comunicación) ayuda a mantener la comunicación. Involución baja.

En la Tabla 3 se dispone de un resumen de las conclusiones alcanzadas. Por supuesto, estos resultados deben valorarse en su justa medida, como el resultado de una codificación de las razones aducidas por las personas entrevistadas acerca de los cambios observados en sus redes sociales.

\begin{tabular}{|c|c|c|}
\hline Motivos del cambio observado & Evolución & Involución \\
\hline \multicolumn{3}{|l|}{ Reproducción material } \\
\hline Trabajo & $* * *$ & \\
\hline Residencia & & ** \\
\hline \multicolumn{3}{|l|}{ Espacios de interacción } \\
\hline Cursos & $* *$ & \\
\hline Asociaciones & & $* *$ \\
\hline Discoteca & $*$ & \\
\hline Espacios culto & & $*$ \\
\hline Deporte étnico & & $* *$ \\
\hline Deporte & $*$ & \\
\hline \multicolumn{3}{|l|}{ Ciclo vital } \\
\hline Matrimonio homófilo & & $* * *$ \\
\hline Matrimonio heterófilo & $* *$ & \\
\hline Divorcio & & ** \\
\hline Nacimiento & & $* *$ \\
\hline Muerte & $*$ & \\
\hline \multicolumn{3}{|l|}{ Transitividad } \\
\hline Transitividad positiva & - & - \\
\hline Conflictos & - & - \\
\hline \multicolumn{3}{|l|}{ Viajes y visitas } \\
\hline Viajes & & $* *$ \\
\hline Visitas & & $*$ \\
\hline
\end{tabular}




\begin{tabular}{|l|c|c|} 
Error & - & - \\
\hline Limitación 45 & - & - \\
\hline Medios de comunicación & & $*$ \\
\hline Teléfono & & $*$ \\
\hline Messenger
\end{tabular}

Tabla 3. Resumen de las razones del cambio observado y valoración de su impacto en la dirección del cambio.

\section{Conclusiones e investigación futura}

El estudio de las redes personales nos sitúa en una posición privilegiada para entender el cambio social y cultural en todas sus dimensiones. Las condiciones institucionales del contexto de recepción, la cultura, el ciclo vital pero también el azar, las decisiones individuales y las dinámicas emergentes propias de la transitividad positiva y negativa, todo ello combinado en diferentes proporciones, hacen de cada caso algo diferente y único.

A través de la comparación de las dos oleadas a nivel individual y a nivel agregado por colectivos ha sido posible establecer tanto un modelo general de cambio como diferentes modalidades de adaptación por parte de cada colectivo estudiado ${ }^{11}$.

El colectivo argentino manifiesta una notable capacidad para insertarse en la sociedad de destino. Estas personas deciden quedarse en España y actúan en consecuencia, limitando conscientemente las relaciones con otros argentinos.

El colectivo amazig, con una larga trayectoria de emigración y con personas de segunda generación, manifiesta una modalidad de adaptación muy interesante, pues por una parte conocen a españoles/catalanes (básicamente a través del trabajo, estudios o cursos y vecinos) pero por otra parte renuevan los lazos con personas de Marruecos a través de matrimonios "asimétricos" por lo que se refiere a la posición en la cadena migratoria. La religión quizás sea un factor importante en este caso.

El colectivo dominicano manifiesta una resistencia notable, a pesar de hablar español, a romper sus lazos con la República Dominicana y en los casos estudiados, la asociación y el softball constituyen un elemento importante de mantenimiento y desarrollo de estos lazos étnicos tanto en origen como en destino. Será interesante ver qué pasará con la segunda generación.

\footnotetext{
11 Los diferentes tipos de redes sociales y el apoyo social disponible de inmigrantes en España son estudiados por Maya Jariego (2006), Aparicio et al. (2005) y de Miguel et al. (2007).
} 
El enormemente diverso colectivo procedente de Gambia y Senegal, el más reciente y predominantemente masculino por ahora, continúa avanzando en el proceso migratorio, evolucionando del tipo I al tipo III y en algunos casos al tipo IV. La creación de asociaciones "étnicas", diola en este caso, también tiene efectos involutivos (Tipo II).

En conjunto, gracias a la metodología desarrollada y los datos recogidos somos capaces de modelizar los tipos de cambio conservando la complejidad de cada uno de ellos. Insistimos que estos cambios observados son el resultado agregado de todos los factores descritos, de forma que estos cambios implican o conllevan también cambios en la identificación étnica, en el uso de la lengua y en otros ámbitos de la vida de estas personas.

Por supuesto, este estudio presenta importantes limitaciones. En primer lugar el reducido número de casos estudiado no nos permite generalizar las conclusiones alcanzadas, sino solamente apuntar hipótesis de futuro que precisarán investigaciones diseñadas ad hoc para poder llegar a resultados concluyentes.

Por otra parte, el tiempo transcurrido entre las dos oleadas, aún siendo significativo, es demasiado corto para poder apreciar cambios de más largo alcance.

Entendemos que la investigación futura tiene que abordar al menos dos problemas pendientes. Uno, la integración de estas redes personales en redes sociocéntricas que permitan evaluar mejor los efectos de terceras personas y dinámicas que no podemos captar con los datos disponibles, en la línea desarrollada por Snijders et. al. con SIENA (2008). Dos, el desarrollo de metodologías que nos permitan depender menos de los sesgos cognitivos y de la frecuencia de interacción para elicitar redes personales. Esperamos sinceramente poder contribuir a este reto.

\section{Bibliografía}

Aparicio, R. y A. Tornos (2005). Las redes sociales de los inmigrantes extranjeros en España. Madrid: Ministerio de Trabajo y Asuntos Sociales.

Berry, John (2003). "Conceptual Approaches to Acculturation" en Chun, Kevin M. et. al., Acculturation. Advances in Theory, Measurement and Applied Research. Washington DC: American Psychological Association.

Bourdieu, Pierre (1977). Outline of a Theory of Practice. New York: Cambridge University Press.

Brandes, Ulrik; Jürgen Lerner; Miranda J. Lubbers; Chris McCarty \& José Luis Molina (2008). "Visual Statistics for Collections of Clustered Graphs". In: 
Proceedings of the IEEE Pacific Visualization Symposium (PacificVis'08), pp. 47-54. IEEE Computer Society.

Burt, Ronald S. (1992). Structural Holes: The Social Structure of Competition. Cambridge: Harvard University Press.

Coleman, J. (1990). Foundations of Social Theory. Cambridge, MA: Harvard University Press.

de Federico, Ainhoa (2002). "Presentación: Tendiendo puentes, de Lilnet a Redes", Revista Redes, Vol.3, \#1, Septiembre-Noviembre. [http://revista-redes.rediris.es].

De Miguel Luken, Verónica \& Miguel Solana Solana; dirigido por Àngels Pascual de Sans (2007). Redes sociales de apoyo. La inserción de la población extranjera. Bilbao: Fundación BBVA.

Ferrand, Alexis (2002). "Las comunidades locales como estructuras meso", Revista Redes, Vol. 3, \#4, Septiembre-Noviembre [http://revistaredes.rediris.es].

Giddens, Anthony (1987 [1967]). Las nuevas reglas del método sociológico [New Rules of sociological method: A positive critique of interpretative sociologies]. Buenos Aires: Amorrortu Ediciones. Buenos Aires.

- (1987). Social Theory and Modern Sociology. Oxford: Polity Press.

Lerner, Juergen \& Ulrik Brandes (2007). "Comparing Networks by their Group Structure with an application to acculturation networks", XXVII Sunbelt'07 Corfu, Greece May 1-6. [www.egoredes.net].

Lerner, Juergen, Ulrik Brandes, Miranda J. Lubbers, José Luis Molina \& Chris McCarty (2008a). "Visualizing Tendency and Dispersion in Collections of Attributed Networks", XXVIII Sunbelt'08, January 24-27, Sant Pete, Florida, USA. [www.egoredes.net].

Lubbers, Miranda Jessica, José Luis Molina \& Chris McCarty (2007). "A typology of personal networks of immigrants in Spain", XXVII Sunbelt'07 Corfu, Greece May 16 [www.egoredes.net].

Maya Jariego, I. (2006). "Mallas de paisanaje: el entramado de relaciones de los inmigrantes", en Pérez Pont, J. L. (Ed.). Geografías del desorden. Migración, alteridad y nueva esfera social, 257-276. Universidad de Valencia: Valencia.

Maya Jariego, I. \& Holgado, D. (2005)."Lazos fuertes y proveedores múltiples de apoyo: comparación de dos formas de representación gráfica de las redes personales", Empiria. Revista de metodología de ciencias sociales, 10, 107-127.

McCarty, Christopher (2002. "Structure in Personal Networks", JoSS. Volume 3. [http://www.cmu.edu/joss/content/articles/volume3/McCarty.html].

McCarty, Christopher; Molina, José Luis; Aguilar, Claudia y Laura Rota (2007). "A Comparison of Social Network Mapping and Personal Network Visualization", Field Methods, Vol. 19 (2) May (145-162).

Molina, José Luis (2005). "El estudio de las redes personales: contribuciones, métodos y perspectivas", Empiria, Julio-Diciembre 10 (71-106). 
Molina, José Luis, Chris McCarty, Claudia Aguilar y Laura Rota (2007). "La estructura social de la memoria", en Lozares C. (ed.) Interacción, Redes Sociales y Ciencias Cognitivas. Barcelona: Editorial Áurea.

Portes, A.; Manning, R. (1986). "The Immigrant Enclave: Theory and Examples", en J. Nagel y T. Olzak (eds.), Competitive Ethnic Relations. Orlando: Academic Press.

Snijders, Tom A.B.; Steglichz, Christian E.G. \& Gerhard G. van de Buntx (2008)."Introduction to Actor-Based Models for Network Dynamics", Social Networks, en publicación.

Terhell, EL; van Groenou, MIB; van Tilburg, T (2007). "Network contact changes in early and later postseparation years", Social Networks, Vol. 29, 1 (11-24).

Terhell EL, van Groenou MIB, van Tilburg T (2004)."Network dynamics in the longterm period after divorce", Journal of Social and Personal Relationship, Vol. 21, 6 (719-738). 